\title{
Effect of aquatic training with and without weight on selected physiological variables among volleyball players
}

\author{
K. Kamalakkannan ${ }^{1}$, M. Balaji ${ }^{2}$, N. Vijayaragunathan ${ }^{3}$ and C. Arumugam ${ }^{4}$ \\ ${ }^{1}$ Arunai engineering college, Tiruvannamalai, TN; ${ }^{2}$ Kamban engineering college, Tiruvannamalai-606603 TN, India \\ ${ }^{3}$ Arts \& Science College, Melasivapuri 622403, TN, India \\ ${ }^{4}$ Tamil nadu Physical Education and Sports University, Chennai 600006, TN, India \\ kkk_kkkn@yahoo.co.in
}

\begin{abstract}
The purpose of this study is to enhance sports performance: the objective is to analyse the effect of aquatic training with and without weight on selected physiological variables among volleyball players. To achieve this 60 physically active and interested undergraduate engineering volleyball players are selected as subjects and their age ranged between 18 and 20 years. The subjects are categorized into three groups randomly viz. Control group (CG), Aquatic training with weight group (ATWG), Aquatic training without weight group (ATWOG) and each group comprises of 20 subjects. Control group was not exposed to any training. Both experimental groups underwent their respective experimental treatment for 12 weeks, 3 days per week and a session on each day. Breath holding time, resting pulse rate were taken as variables for this study. The collected data was analyzed using analysis of covariance (ANCOVA) and Scheffee's post hoc test. The result reveals significant differences in all the selected physiological variables among ATWG and ATWOG pointing towards the use of aquatic training for performance improvement.
\end{abstract}

Keywords: Sports physiology, aquatic training, volleyball players.

\section{Introduction}

Water resistance strongly affects untrained people in water-exercise. Unskilled movement may increase the energy, via anaerobic glycols, required to overcome the resistance to movement through the water (Shono et al., 2001). The physiological benefits of running are well documented and noteworthy; its overuse has contributed to a wide range of foot and leg injuries (Glass et al., 1995). In general, heart rates during deep-water exercise are approximately 17 beats per minutes lower than during comparable exercise on land (McArdle wd et al., 1991). Aquatic running or jogging, when supported by floatation devices, offers additional benefits, most notably, the maintenance of rapid stride frequencies without the impact of landing and coordinated movements between the arms and legs (Cassidy \& Nielsen, 1992; Tovin, 1994). Deep water running has been shown to compare favorably with land-based exercise. Maximum oxygen uptake values for aquatic running ranged from $83-89 \%$ when compared to the values obtained from running on land. Maximum heart rate values for aquatic running ranged from $89-95 \%$ of values measured on land (Wilder, 1993; Woolfenden, 1994). Many previous studies have reported metabolic and cardio respiratory responses during walking and jogging in a pool (Eva et al., 1978; Whitley \& Schoene, 1987; Bishop et al., 1989; Ritchie \& Hopkins, 1991; Town \& Bradley, 1991; Gehring et al., 1992) but it was difficult to fix the physical and physiology intensity for walking and jogging in a pool, due to water density, approximately 800 times higher than air (Prampero, 1986). Heart rate has been reported to decrease during head-out water immersion exercise compared with air (Avellini et al., 1983; Christie et al., 1990; Connelly et al., 1990, Norsk et al., 1990). The mechanism responsible for the lower heart rate during immersion is the distribution of blood volume from the periphery to the central region. The increased hydrostatic pressure of water, concomitant with peripheral vasoconstriction to reduce heat loss forces peripheral blood into the thorax. This result in an enhanced venous return and a decreased stroke volume while maintaining cardiac output (Avellini et al., 1983). The Flow mill is able to measure various physiological responses during water walking under fixed load conditions, and various studies have been conducted (Onodera et al., 1992; Kanaya et al., 1993; Hotta et al., 1993 a, b, 1994; 1995; Migita et al., 1994, 1996; Takaoka et al., 1999). They found that approximately one-half to one-third of the speed is needed to walk or jog across a pool through waist-deep water at the same level of energy expenditure as treadmill-walking and jogging on land (Gleam \& Nicholas, 1989). The respiratory index in the aqueous environment is similar to the one found on land in sub maximal levels and in the maximal effort (Town \& Bradely, 1991; Dowser et al., 1998; Butts et al., 1991; Gehring et al., 1997; Connelly et al., 1990). Hormonal changes have been observed with sustained periods of water immersion. Energy expenditure in water depends more on energy expended to overcome drag compared to exercise on land (Holmer, 1972). In water walking, it has also been hypothesized that differences in skills for walking through
Research article

CIndian Society for Education and Environment (iSee)
"Sports physiology: volleyball payers" http://www.indjst.org
Kamalakkannan et al. Indian J.Sci.Technol. 
the water strongly affect energy expenditure (Shono et al., 2001). Methods

To achieve this, 60 physically active and interested undergraduate engineering volleyball players were randomly selected as subjects and their age ranged between 18 and 20 years. The subjects are categorized into three groups

randomly viz. Control group (CG), Aquatic training with weight group (ATWG), Aquatic raining without weight group (ATWOG) and each group had 20 subjects. The resting pulse rate data was collected by the finger tip pulse oximeter and the breath holding time was collected manually. There is no specific instrument for measuring the breath holding time. Control group was not exposed to any training. Both experimental groups underwent their respective experimental treatment for 12 weeks, 3 days per week and a session on each day. Weight is assigned by (1 RM) test for each individual in (ATWG). The subjects were instructed to wear a weight jacket which is filled with sand in appropriate weights. Warming up exercise was performed in ground and water. The water level was above the hip level. The water temperature and climatic condition could be controlled; hence theses aspects were kept as one of the limitation of the study. The ATWG and ATWOG groups initially performed the warming up exercises. After that both the groups performed the following aquatic exercises. 1. Single leg jump (alternative leg), 2. Double leg jump; 3. High knee action; 4. Walking; 5. Aerobic exercise; 6. Pedaling. These exercises were performed for $45 \mathrm{~min}$ in a day and for $3 \mathrm{~d}$ per week. Observations were made for 12 weeks and then post test data were taken.

Statistical analysis

Means and standard deviations were calculated for breath holding time, resting pulse rate for each training group. ANCOVA and Scheffee's post hoc test were used to examine significance between the variables of testing groups (CG, ATWG \& ATWOG). Statistical significance was set to a priority at $p=0.05$. All statistical tests were calculated using the statistical package for the social science (SPSS) for windows (Version 15).

Results

In the initial data analysis, F-
Table 3. Scheffe's post-hoc test for means differences between group of breath holding time

\begin{tabular}{|c|c|c|c|c|}
\hline $\begin{array}{c}\text { Control } \\
\text { group }\end{array}$ & $\begin{array}{c}\text { With } \\
\text { weight }\end{array}$ & $\begin{array}{c}\text { Without } \\
\text { weight }\end{array}$ & $\begin{array}{c}\text { Means } \\
\text { difference }\end{array}$ & C.I. \\
\hline 0.54 & 0.64 & & $0.10^{*}$ & \multirow{2}{*}{0.10} \\
\hline 0.54 & & 0.69 & $0.15^{*}$ & \multirow{2}{*}{0.65} \\
\hline & 0.64 & 0.69 & 0.05 & \\
\hline
\end{tabular}

Scheffe's post-hoc test for means differences between group of resting pulse rate

\begin{tabular}{|l|l|l|l|l|}
\hline 69.94 & 71.75 & & $1.81^{*}$ & \\
\cline { 1 - 4 } 1.80 & \\
\hline & & 66.55 & $3.39^{*}$ & \multirow{2}{*}{1.75} \\
\hline
\end{tabular}

"Sports physiology: volleyball payers" http://www.indjst.org
Vol. 3 No. 5 (May 2010)

ISSN: 0974- 6846 \& co-variance of pre
breath holding time

\begin{tabular}{|l|c|c|c|c|c|c|c|c|}
\hline & CG & ATWG & ATWOG & $\begin{array}{c}\text { Source of } \\
\text { variance }\end{array}$ & $\begin{array}{c}\text { Sum of } \\
\text { squares }\end{array}$ & DF & $\begin{array}{c}\text { Means } \\
\text { squares }\end{array}$ & F-Ratio \\
\hline $\begin{array}{l}\text { Pre-test } \\
\text { means } \\
\text { SD }( \pm)\end{array}$ & 0.56 & 0.52 & 0.55 & BG & 0.017 & 2 & 0.009 & \multirow{2}{*}{0.14} \\
\cline { 2 - 8 } $\begin{array}{l}\text { Post-Test } \\
\text { means } \\
\text { SD }( \pm)\end{array}$ & 0.57 & 0.22 & 0.24 & WG & 3.32 & 57 & 0.05 & 0.3 \\
\cline { 2 - 9 } $\begin{array}{l}\text { Adjusted } \\
\text { post-test } \\
\text { means }\end{array}$ & 0.54 & 0.64 & 0.60 & BG & 0.04 & 2 & 0.02 & \multirow{2}{*}{$4.25^{*}$} \\
\hline
\end{tabular}

Table 2. Resting pulse rate

Test was applied to test pre and post test means between the groups of control, Aquatic training with weight and Aquatic training without weight groups on selected hysiological variables of breath holding time, resting rate (Table 1-3; Fig.1, 2). The F-value needed for 列 0.05 level was 3.15 . The physicted mean on selected resting pulse rate were $0.14,0.13$ respectively. It was found to be in significant. In post test analysis the F-ratio on the variables such as breath holding time, resting ulse rate were 0.3 , and 14.42 respectively.

The F-value needed for significance for df $(2,57)$ at leve variables namely breath significant improvement. The primary aim of analysis of covariance is adjusting the differences in pre test means with post test means between the control, ATWG and ATWOG .The F-value needed for significance for $\mathrm{df}(2$, at 0.05 level was 3.16. The F-value obtained from testing the adjusted means between the CG, ATWG and ATWOG groups on. Breath holding time, resting pulse rate were 4.25 , and 25.59 It was found to be significant

\section{Discussion}

Several research studies suggest that aquatic training may be valuable for determining the physiological variables search as resting heart rate, maximum oxygen consuming, cardiac output sub maximal physiological responses, the respiratory index, chronic physiological response in water immersion. Recovery from

Kamalakkannan et al. Indian J.Sci.Technol. 
Fig. 1. Analysis of variance \& co-variance of pre, post \&

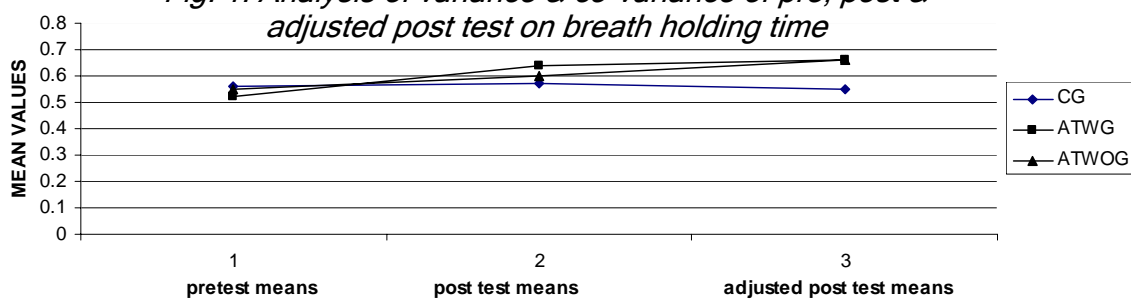

Fig. 2. Analysis of variance \& co-variance of pre, post \& adjusted post test on resting pulse rate

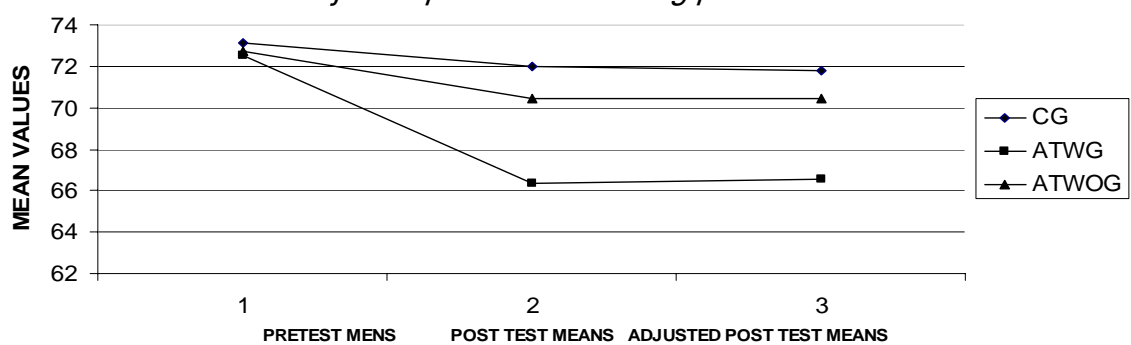

resistance training and rehabilitation of both sports specific athletes and injured athletes can be done in this method. Most of the aquatic researchers had to work with the aquatic running, aquatic plyometric training, deep water running, aquatic tumbles and aquatic treadmill to improve the physiological performance of the players. In this present study the method of aquatic training with weight (i.e., aquatic training with wearing the weight jacket filled with sand) is implemented to investigate the resting pulse rate and breath holding time. There is some scientific evidence supporting the success of athletes by aquatic based training. In the 1990s, there was a flurry of scientific research investigating the viability of deep-water running/jogging as an aquatic training modality. In general, the majority of these studies suggest that adding deep-water running to an athlete's training regimen has the potential to increase fitness and ultimately improve performance (Burns \& Lauder, 2001; Shomo et al., 2001) clearly indicates that experience in moving through the water strongly affects the physiological responses to water-exercise. In the study (Johnson et al., 1977) the depressed heart rate was noted in all subjects after entering the water and standing submerged to the shoulder level. In the present study the resting HR in water were 4.7 beats/min lower than those on land. Kruel (2000) analyzed the $\mathrm{VO}_{2}$ and $\mathrm{HR}$ responses to five water exercises performed in an aquatic environment at two distinct water depths, the shoulder and the navel. This significantly lower resting HR in the water as compared to that on land is thought to be largely due to the effect of hydrostatic water pressure exerted against the legs and torso (Arborelius et al., 1972; Hong et al., 1969). The hydrostatic pressure causes an immediate increase in venous return, right atrium pressure and, hence, stroke volume. Increased stroke volume allows for the maintenance of cardiac output with lower HR (Christie et al., 1990) it seems reasonable that a lower HR during
Vol. 3 No. 5 (May 2010)

ISSN: 0974- 6846

water exercise may have caused a greater venous return, a higher stroke volume and a higher cardiac output in water immersion (Farhi \& Linnarsson, 1977). The athlete should train at heart rate 17 to 20 beats per minutes lower than on land. (MC Ardle et al., 1991) Maximum heart rate values for aquatic running ranged from $89 \%-95 \%$ of values measured in land. (Wilder \& Brennun, 1993) Even though aquatic training is mechanically different from landbased running (Wilber et al., 1996; Bushman et al., 1997) it was concluded that long term aquatic training has the potential to stimulate the physiological adaptations needed to maintain running economy. In this present study, the results show that there was a significant difference between control and Aquatic training with weight group, control and Aquatic training without weight groups \& Aquatic training with weight and Aquatic training without weight groups.

\section{Conclusion}

Regarding the resting pulse rate, there was a significant difference occurred among 3 groups of which Aquatic training with weight group is the top, followed by Aquatic training without weight compared to control group. In breath holding time, there was a significant difference occurred between the control and Aquatic training with weight group in which the Aquatic training with weight group is the top, followed by Aquatic training without weight and control group. Clearly, the ATWG performed best followed by ATWOG and CG.

\section{Reference}

1. Arborellius M, Balldin UI, Lilja G and Lundgren CEG (1972) Hemodynamic changes in man during immersion with the head above water. Aerospace Med. 43, 592-598.

2. Vellini BA, Shapiro Y and Pandolf KB (1983) Cardiorespiratory physical training in water and on land. Eur. J. Appl. Physiol. 50, 255-263.

3. Bishop PA, Frazier S, Smith J and Jacobs D (1989) Physiologic responses to treadmill and water running. Phy. Sportsmen. 17, 87-94.

4. Butts NK, Tucker M and Grening C (1991) Physiologic responses to maximal treadmill and deep water running in men and women. Am. J. Sports Med. 19, 612-614.

5. Cassaday SL and Nielsen DH (1992) Cardio respiratory responses of healthy subjects to Calisthenics performed on land versus in water. Phys. Ther. 72, 532.

6. Christie JL, Sheldahl LM, Tristani FE, Wann LS, Sagar KB, Levandoski SG, Ptacin MJ, Sobocinski KA and Morris RD (1990) Cardiovascular regulation during head-out water immersion exercise. J. Appl. Physiol. 69, 657-664.

7. Connelly TP, Sheldahl LM, Rristani FE, Levandoski SG, Kaljhoff RK, Hoffman MD and Kalbfleisch JH (1990) Effect of increased central blood volume with water immersion
Research article

CIndian Society for Education and Environment (iSee)
"Sports physiology: volleyball payers" http://www.indjst.org
Kamalakkannan et al. Indian J.Sci.Technol. 
on Plasma catecholamines during exercise. J Appl. Physiol. 69(2), 651-656.

8. Dowzer CN, Reilly T and Cable NT (1998) Deep and shallow water running on spinal shrinkage. Br. J. Sports Med. 32, 44-48.

9. Di Prampero PE (1986) The energy cost of human locomotion on land and in Water. Int. J. Sports Med. 7, 5572.

10. Evans BW, Cureton KJ and Purvis JW (1978) Physiological responses to walking and jogging in water. Res. Q. 49, 442-449.

11. Farhi LE and Linnarsson D (1977) Cardiopulamonary readjustments during graded immersion in water at $35^{\circ} \mathrm{C}$. Respir. Physiol. 30, 35-50

12. Glass B, Wilson D, Blessing S and Miller E (1995) A physiological comparison of suspended deep water running to hard surface running. J. Strength Conditioning Res. 9(1), 17-21.

13. Gehring M, Keller B and Brehm B (1992) Physiological responses to deep water running in competitive and noncompetitive runners. Med. Sci. Sports Exerc. 24, S23.

14. Gleim GM and Nicholas JA (1989) Metabolic costs and hearts rate responses to treadmill walking in water at different depths and temperatures. Am. J. Sports Med. 17, 248-252.

15. Gehring MM, Keller BA and Brehm BA (1997) Water running with and without a flotation vest in competitive and recreational runners. Med. Sci. Sports Exerc. 29, 1374-1378.

16. Hong S, Cerretelli P, Cruz J and Rahn H (1969) Mechanics of respiration during submersion in water. $J$. Appl. Physiol. 27, 535-538.

17. Hotta N, Muraoka Y, Ogaki T, Kanaya S, Fujishima K, Hong JP and Masuda T (1993a) Cardiovascular responses to treadmill (flowmill) walking in water. Kurume J. Health Phy. Edu. 1, 19-23.

18. Hotta N, Ogaki T, Kanaya S and Hagiwara H (1993b) Exercise treatment to low physical fitness level's patients in water. J. Health Sci. 15, 57-61.

19. Hotta N, Ogaki T, Kanaya S, Fujis hima K and Hagiwara $\mathrm{H}$ (1994) Exercise prescription for aged men and women in water. Descente Sports Sci.15, 78-83.

20. Hotta N, Ogaki T, Kanaya S, Fujis hima K and Hagiwara H (1995) Exercise prescription with a new mode of exercise (flowmill) in water. Bull. Phy. Fitness Res. Inst. $88,11-17$

21. Holmer I (1972) Oxygen uptake during uptake during swimming in man. J. Appl. Physiol. 33, 502-509.

22. Johnson BL, Stromme SB, Adamczyk JW and Tennoe KO (1977) Comparison of oxygen uptake and heart rate during exercise on land and in water. Phys. Ther. 57, 273278.

23. Kanaya S, Hotta N, Ogaki , Fujishima K, Shono T, Shimzu T, Hagiwara H and Fujimo T (1993) New exercise ECG by treadmill walking in water, using the flow water training system.J. Health Sci. 15, 69-74.

24. Kruel LFM (2000) Alteracoes fisiologicas e biomecanicas em individuos praticando exercicios de hidroginastica dentro e for a d'agua. Unpublished doctoral dissertation, Federal University of Santa Maria, Santa Maria, Brazil.
Vol. 3 No. 5 (May 2010)

ISSN: 0974- 6846

25. McArdle wd, katch FI and Katch VL (1991) Exercise physiology; energy, nutrition and human performance. $3^{\text {rd }}$ ed. Philadelphia, PA; Lea Febiger.

26. Migita T, Muraoka Y, Hotta N, Ogaki T, Kanaya S, Fujishma K and Masuda T (1994) Cardio-respiratory responses during water and land walking. Kurume $J$. Health Phy. Edu. 2, 25-30.

27. Migita T, Hotta N, Ogaki T, Kanaya S, Fujishima K and Masuda T (1996) Comparison of the physiological responses to treadmill prolonged walking in water and on land. Japan J. Phys. Edu. 40, 316-323.

28. Norsk P, Bonde-Petersen F and Christensen NJ (1990) Catecholamines, circulation and the kidney during water immersion in humans. J. Appl. Physiol. 69, 474-484.

29. Onodera S, Kimura K, Miyachi M, YOnetani S and Hara H (1992) Influence of viscous resistance on heart rate and oxygen uptake during treadmill walking in water and on land. Japan J. Aerospace Environ. Med. 29, 67-72.

30. Ritchie SE and Hopkins WG (1991) The intensity of exercise in deep water running. Int. J. Sports med. 12(27), 20.

31. Tovin BJ, Wolf SL, Greenfield BH, Crouse $\mathrm{J}$ and Woodfin BA (1994) Comparison of the effects of exercise in water and on land on the rehabilitation of patients with intraarticular anterior cruciate ligament reconstructions. Phy. Therapy Forum. 74, 710-715.

32. Town GP and Bradley SS (1991) Maximal metabolic responses to deep and shallow water running in trained runners. Med. Sci. Sports Exer. 23(2), 238-241.

33. Shono T, Fujishima K, Hotta N, Ogaki $\mathrm{T}$ and Ueda $\mathrm{T}$ (2001) Physiological responses to water-waking in middle aged women. J. Physiol. Anthropol. Appl. Human Sci. 20(2), 119-123.

34. Takaoka I, Ohnishi T, Okamura S and Suzuki D (1999) The physiological responses and RPE to different water flow and belt velocities during "flowmill" walking in water. J. Health Sports Sci. Juntendo Univ. 3, 61-67.

35. Whitley JD and Schoene LL (1987) Comparison of heart rate responses; water walking versus treadmill walking. Phys. Ther. 67,1501-1504

36. Wilder RP, Brennan DK and Schotte DE (1993) A standard measure for exercise prescription for aqua running. Am. J. Sports Med. 21, 45.

37. Woolfenden JT (1994) Aquatic physical therapy approaches for the extremities. In: Orthopedic physical therapy clinics of North America: aquatic therapy. Cirullo JA (Eds). Philadelphia: W.B. Saunders. p:209.
"Sports physiology: volleyball payers" http://www.indjst.org
Kamalakkannan et al. Indian J.Sci.Technol. 